\title{
12 BAZAAR BY DESIGN: Managing Interfirm Exchanges in an Open Source Service Network
}

\author{
Joseph Feller \\ University College Cork \\ Cork, Ireland \\ Patrick Finnegan \\ University College Cork \\ Cork, Ireland \\ Brian Fitzgerald \\ University of Limerick \\ Limerick, Ireland \\ Jeremy Hayes \\ University College Cork \\ Cork, Ireland
}

\begin{abstract}
As in many other sectors, competitive necessities are driving open source software companies to participate in cooperative business networks in order to offer the complete product and service offerings demanded by customers. This paper examines one such emerging business network archetype: an open source service network (OSSN). This type of business network is of particular interest as it not only addresses key challenges vis-à-vis OSS commercialization, but operates in a manner that overcomes exchange problems among participants by relying primarily on social mechanisms. The paper reveals the manifestation of social mechanisms in OSSNs and how these are used for coordinating and safeguarding exchanges between firms. Specifically, we illustrate the importance of (1) restricted access, (2) assessing the reputation of others, (3) a shared macroculture (goals and norms), and (4) collective sanctions for punishing firms who violate these goals and norms.
\end{abstract}

Please use the following format when citing this chapter:

Feller, J., Finnegan, P., Fitzgerald, B., and Hayes, J., 2008, in IFIP International Federation for Information Processing, Volume 267, Information Technology in the Service Economy: Challenges and Possibilities for the $21^{\text {st }}$ Century, eds. Barrett, M., Davidson, E., Middleton, C., and DeGross, J. (Boston: Springer), pp. 173-188. 
Keywords

Open source service network, social mechanisms, network governance, interorganizational systems

\section{INTRODUCTION}

Advancements in the provision of open source software (OSS) have come to closely resemble complex product and service offerings in many other sectors. Davidow and Malone (1992) predicted that the challenges of the $21^{\text {st }}$ century would require organizations to quickly and globally deliver a high variety of customized products and services, while Stafford (2002) documented that the market forces surrounding such offerings require organizations to deliver products and services to market so rapidly that they would have to align themselves in IT-mediated partner networks in order to meet customer requirements.

OSS is best defined by its central characteristic: the development, distribution, acquisition, and use of software based on collaboration and sharing rather than proprietary restrictions (Feller and Fitzgerald 2002). Commercial strategies, thus, focus on the provision of value-adding services around the software product (Fitzgerald 2006). This allows third-party service providers to engage in level-field competition with the software creators by leveraging the open nature of the source code. Such low barriers to entry in OSS service provision (see Woods and Guliani 2005) have led to the proliferation of technology-driven OSS microfirms offering specialized products and services. However, such firms cannot always meet customer requirements for end-to-end system implementation and support.

Commercialization strategies for OSS point to a need to (1) build business models capable of a whole product (Moore 1999) approach to software and service delivery, and (2) marry community-driven development capabilities with high-levels of sector knowledge in vertical business domains. In other words, companies seek to productize open source software to meet the needs of both enterprises and end-users by offering support, implementation, modification, and related services (Woods and Guliani 2005). Such challenges suggest the need for new organizational forms, such as cooperative business networks of OSS companies (Fitzgerald 2006). Nevertheless, research on the commercialization of OSS has focused narrowly on revenue generation models (e.g., Krishnamurthy 2005; Markus et al. 2000), and has been dominated by studies of single firms, whether OSS start-ups such as RedHat and JBoss (e.g., Krishnamurthy 2005) or very large multinationals like Apple, IBM, and Sun (e.g., West 2003), neglecting networkbased business models, although they are observable in practice.

We have identified one type of OSS business network, which represents what Clemons and Row (1992) term a "move-to-the middle," networks of organizations that interact in order to deliver value to the end consumer. We label such networks open source service networks (OSSNs). OSSNs typically seek to meet what Woods and Guliani (2005) describe as the challenge of productizing OSS by offering support, implementation, modification, and related services. They are characterized by their reliance on information and communication technologies to mediate collaboration and communication and have grown in an organic fashion strongly informed by the practice of community-based OSS projects. While being legal entities, they have avoided formal 
or legal contracts to govern interfirm coordination. This type of interfirm coordination has been termed network governance (see Jones et al. 1997).

This paper examines Zea Partners, a business network of firms developing software solutions and selling services around the Zope application server. The network enables participants to, collectively, undertake larger commercial contracts than they would be able to do individually. However, they primarily use social, rather than formal or legal mechanisms, to enable interfirm exchanges. Although this appears counterintuitive, the study demonstrates the role of social mechanisms in enabling network effectiveness. We use the work of Jones et al. (1997) on network governance and De Wever et al. (2005) on network effectiveness to investigate how social mechanisms are used to overcome exchange problems and enable the access to, and transfer of, strategic resources among network participants. The paper concludes by modeling how social mechanisms are used to overcome exchange problems in an open source service network.

\section{BACKGROUND}

\subsection{Open Source Service Networks}

We define an open source service network as

\section{A network of firms that collaborate in order to service customer software needs based on open source solutions.}

To clarify the definition, network is understood to mean a collaborative network with interdependencies between member firms and a shared identity. This differentiates OSSNs from non-interdependent groupings such as third-party directories and portals listing OSS firms (e.g., SourceForge.net Marketplace). Furthermore, the primary purpose of the network is to commercially service customer software needs based on open source solutions. This differentiates OSSNs from noncommercial groupings such as advocacy networks, nonprofit foundations development hosts (e.g., Apache Software Foundation), and research communities, as well as business networks offering solely proprietary solutions (e.g., Microsoft Partner Program).

OSSNs are interorganizational networks that facilitate the flow of resources among nonhierarchical and legally separate entities in order to meet challenges that are often beyond the capabilities of individual firms. Specifically, OSSNs exist to support member firms in their efforts to deliver whole products and productize open source software by offering support, implementation, modification, and related services to consumers, thus addressing the productizing challenge facing open source software outlined above. Therefore, OSSNs are relevant to the commercialization of OSS and consequently significant for practitioners.

As will be discussed later, research has shown that the effective operation of any network is dependent on overcoming exchange problems among participants. While many business networks rely primarily on formal or legal mechanisms, most OSS development communities rely on informal (social) mechanisms. Our observations of OSSNs reveal that they appear to be shaped by the informal ethos and operational style of the OSS communities from which they originated, and with which they continue to interact. Addi- 
tionally, OSSNs have inherited much of the IT infrastructure characteristic of OSS communities. Such IT facilitates interaction and makes the communication and collaboration activities of a community persistently visible to all participants, thus enabling the use of social mechanisms to overcome exchange problems. However, OSSNs represent an intersection between the corporate-centered culture of traditional business networks and the community-centered culture of open source software. We, therefore, cannot assume that the operational effectiveness of OSSNs can be achieved using purely formal mechanisms as employed by other business networks; neither can we assume that our understanding of the operation of social mechanisms in OSS communities provides a suitable alternative.

\subsection{Managing Exchanges in Business Networks and OSS Communities}

The benefits of cooperative relationships between independent firms have been advocated for decades (Cash and Konsynski 1985; Finnegan et al. 2003; Henderson 1990; Kaufman 1966; Van de Ven 1976). The reasons for interorganizational cooperation include resource procurement and allocation (Alter and Hage 1993; Clemons and Row 1992; Galaskiewicz 1985), political advantages (Galaskiewicz 1985), risk sharing and acquiring expertise (Alter and Hage 1993), stability (Oliver 1990), legitimacy (Galaskiewicz 1985; Oliver 1990), and efficiency (Clemons and Row 1992; Oliver 1990). Frequently, participants in interorganizational networks believe that collaboration will result in adaptive efficiency, "the ability to change rapidly and at the same time provide customized services or products, and at low cost" (Alter and Hage 1993, p. 274).

Cooperative business relationships are social action systems as they exhibit the fundamental principles of any organized form of collective behavior; members aim to achieve collective and self-interest goals; the division of tasks and functions among members creates interdependent processes; the cooperative entity can act as a unit and has a separate identity from its members (Van de Ven 1976). Nevertheless, such relationships are typified by formal, structured coordination mechanisms and agreements in order for individual organizations to meet their own goals as well as the goals of the cooperative entity (Van de Ven and Walker 1984). While there is some evidence of the use of informal mechanisms to coordinate interorganizational relationships (Jones et al. 1997, 1998), the effectiveness of this approach has not been verified where the business network forms the basis of competitive strategy. Furthermore, the dominance of formal governance is influenced by the fact that the IT infrastructures implemented in the majority of business networks are designed to facilitate transactions (e.g., purchase orders, invoices, payment, etc.) between participants (Timmers 1999), and do not provide the visibility of social action for the effective operation of informal mechanisms.

Interfirm coordination characterized by organic or informal social systems, rather than bureaucratic structures within firms and formal contractual relationships between firms, is labeled network governance (Jones et al. 1997). In contrast to business networks, the use of informal social mechanisms has dominated investigations of exchange conditions and developer relationships in OSS communities (labeled the bazaar by Raymond 2001). In particular, the importance of (1) shared beliefs and values (i.e., macroculture) and (2) reputation has been repeatedly described. The OSS governance 
literature demonstrates that, in contrast to the cooperative business networks described previously, OSS development communities have been characterized by (1) a greater emphasis on collaboration and (2) the use of a wide range of technologies to enable social interaction between community members (see Bergquist and Ljungberg 2004; Feller and Fitzgerald 2002; Gallivan 2001; Markus et al. 2000; Sagers 2004; Szczepanska et al. 2005). As an exemplar of peer production, the OSS phenomenon characterizes an alternative model for organizing, a model that operates without reliance on markets, managerial hierarchies, property, and contracts. Peer production is characterized by the decentralized accumulation and exchange of information, and is seen as potentially superior to traditional hierarchy and market-based models (Benkler 2002, 2006). We consequently adopt a conceptual model for our study that illuminates the unique features of OSS as peer production rather than a traditional model of organizational behavior.

\subsection{Conceptual Model}

Jones et al. (1997) identify four preconditions for network governance: demand uncertainty, customized (asset-specific) exchanges, complex tasks executed under timepressure, and frequent exchanges between partners. They argue that under such conditions, networks develop structural embeddedness, which they define, citing Granovetter (1992, p. 35), as the extent to which a "dyad's mutual contacts are connected to one another," creating both direct and indirect ties between parties. Jones et al. assert that when high levels of structural embeddedness are present, it enables the use of various social mechanisms to resolve exchange problems by coordinating and safeguarding exchanges within networks. These social mechanisms are

1. Restricted access: the "strategic reduction in the number of exchange partners in the network" (Jones et al. 1997, p. 927)

2. Macroculture: a "system of widely shared assumptions and values...that guide actions and create typical behavior patterns among independent entities" (ibid, p. 929)

3. Collective sanctions: "ways in which groups punish members who violate shared norms, values and goals" (ibid, p. 931)

4. Reputation: “estimations of one's character, skills, reliability and other attributes important to exchanges" (ibid, p. 932)

In resolving exchange problems in network governance, Jones et al. propose that coordination is supported by restricted access and macroculture, while safeguarding is supported by restricted access, collective sanctions, and reputation (Figure 1). Nevertheless, while the Jones et al. framework has been widely cited in a number of fields, neither the original framework nor subsequent applications of it provide measures of network effectiveness. However, research on interorganizational systems has provided a more considered conceptualization of network effectiveness. In particular, De Wever et al. (2005) posit that network effectiveness can be operationalized as the ability of networks to provide member firms with sustainable access to strategic or value-generating resources, specifically, the access to strategic resources and transfer or exchange of strategic resources in order to acquire them. By combining the work of Jones et al. and De Wever et al., we arrive at the conceptual model for out study (see Figure 1). 


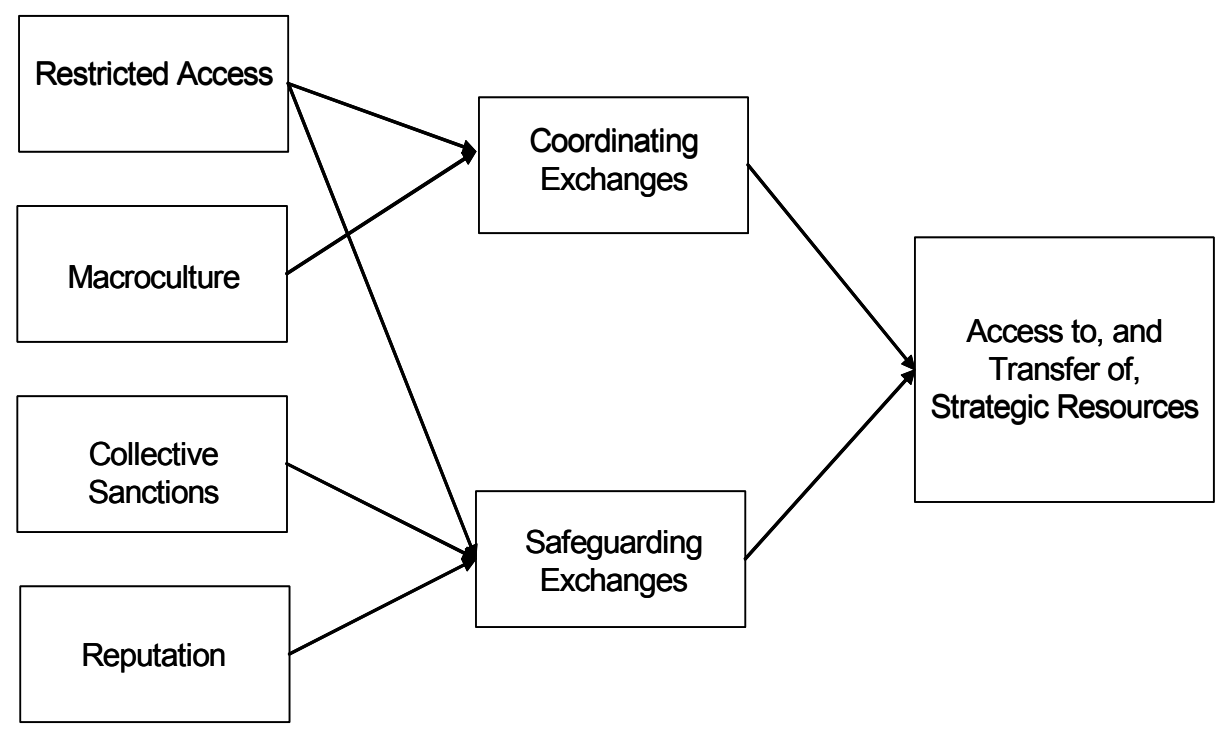

Figure 1. Conceptual Model

\section{STUDY DESIGN}

The objective of our study is to explore the OSSN phenomenon with the specific intention of examining how social mechanisms are used to overcome exchange problems, and thus facilitate network effectiveness in OSSNs.

We adopt a case study method consistent with that of Benbasat et al. (1987) and Yin (1994). We study the OSSN phenomenon in its natural setting, employing multiple data collection methods to gather information from a few entities, without employing experimental control or manipulation. Thus, we follow in the tradition of Eisenhardt (1989) and Madill et al. (2000) by seeking to reveal preexisting, relatively stable and objectively extant phenomena and the relationships among them.

Our OSSN study site, Zea Partners, was founded in 2003 as the Zope Europe Association (ZEA), and changed its name to Zea Partners in 2006. Headquartered in Belgium, Zea Partners operates as an international network of businesses that build software and deliver services around the application server technology called Zope; a well-known piece of open source software widely used for developing content management systems, intranets, portals, and related applications. Zea Partners consists of 25 firms in Europe, America, and Africa. The management team seeks project contracts on behalf of network members and performs network management activities such as marketing and project management. They also develop the network's business strategy in conjunction with the managing partners.

Data for the case study was gathered over a 17-month period and focused on the Zea management team and senior management in eight member companies. Data gathering techniques included 16 interviews and 4 intensive workshops. Interviews were generally of 1 to 2 hours in duration, with follow-up telephone conversations and e-mail used to 
clarify and refine issues that emerged during transcription. Interviews were complemented by comprehensive reviews of documents and presentations and discussions at the workshops.

Interview data was transcribed, generating 133 pages of field notes. Content analysis was undertaken using the grounded theory coding techniques proposed by Strauss and Corbin (1990). The first step (open coding) involved the data being examined line by line to ascertain the main ideas. These data were then grouped by meaningful headings (informed by the conceptual model illustrated in Figure 1) to reveal categories, subcategories, and properties. The next step (axial coding) involved determining hypotheses about the relationships between a category and its subcategories (e.g., conditions, context, action and interaction strategies, and consequences). The focus then turned to the data to assess the validity of these hypothesized relationships. Relational and variational sampling (see Strauss and Corbin 1990) were used to select data for this analysis. This process continued in an iterative manner and resulted in the modification of categories and relationships. Finally, selective coding was undertaken to identify the relationships between categories (constructs) using hypothesized conditions, context, strategies, and consequences. Discriminate sampling (Strauss and Corbin 1990) was used to select data to examine strong and weak connections between categories.

\section{FINDINGS}

The Zea Partners network illustrates the preconditions for network governance as predicted by extant research. The availability of contracts is subject to what Zea's founder calls "valleys and peaks" and the OSS domain experiences constant changes in knowledge and technology, leading to a requirement for information dissemination among firms. These factors produce what Jones et al. (1997) term demand uncertainty. The small size (typically fewer than 10 people), geographic and linguistic limitations, and specialized knowledge of member firms limit the size, location, and complexity of the contracts for which they can bid. The network helps overcome demand uncertainty by allowing companies to pool resources in order to compete for larger and/or global contracts. In competing on the basis of a whole product, the network allows partners to offer a full range of value-chain activities rather than concentrating exclusively on their own specialities. Task complexity is evident as producing the whole product for a wide range of markets and customers requires the inputs of specialists across a range of business functions. Customized exchanges high in human asset specificity are recognizable as member firms collaborate to produce a customized product or service that is not easily transferred. Interfirm routines are learned emergently through the collaborative process rather than by prior agreement. Due to geographical distance, Zea members frequently exchange knowledge in a digital environment. Ongoing interactions between member firms and the mutual sharing of partners, clients, and contacts with the wider OSS community all provide evidence of structural embeddedness.

The network's founder explained that for interfirm coordination, social mechanisms "are the only thing. This is an opt-in system. A large component of the perceived benefit is the reputation improvement from being in the network. Social mechanisms really underpin that." The manner in which social mechanisms were manifest in the network is shown in Table 1. 
Table 1. Manifestation of Social Mechanisms in Zea Partners

\begin{tabular}{|c|c|}
\hline $\begin{array}{l}\text { Restricted } \\
\text { Access }\end{array}$ & $\begin{array}{l}\text { 1. Limiting the number of firms in the network for strategic reasons. } \\
\text { 2. Information on the competencies and activities of others is available to } \\
\text { all members. } \\
\text { 3. Firms wishing to join are assessed on the benefits of their } \\
\text { skills/expertise to the network. } \\
\text { 4. Firms must be known to, or have a prior relationship with, existing } \\
\text { members in order to join the network. } \\
\text { 5. Firms must demonstrate commitment to the ideals of open source } \\
\text { software in order to join the network. }\end{array}$ \\
\hline $\begin{array}{l}\text { Macro- } \\
\text { culture }\end{array}$ & $\begin{array}{l}\text { 1. Sharing a sense of belonging. } \\
\text { 2. Having a common software development philosophy. } \\
\text { 3. Agreeing on accepted ways of doing business. } \\
\text { 4. Maintaining a common set of goals for the network. } \\
\text { 5. Having a sense of mutual interest. } \\
\text { 6. Sharing a sense of common destiny. }\end{array}$ \\
\hline $\begin{array}{l}\text { Collective } \\
\text { Sanctions }\end{array}$ & $\begin{array}{l}\text { 1. Perception that the reputation of a member firm would be damaged if } \\
\text { they behaved unacceptably. } \\
\text { 2. Belief that firms may be excluded from projects if they behave } \\
\text { unacceptably. } \\
\text { 3. Threat that firms would be expelled from the network if they behave } \\
\text { unacceptably. }\end{array}$ \\
\hline Reputation & $\begin{array}{l}\text { 1. Assessing the competence and skills of member firms before doing } \\
\text { business with them. } \\
\text { 2. Evaluating the character and reliability of member firms before doing } \\
\text { business with them. } \\
\text { 3. Expecting others to fulfil their obligations because they are members of } \\
\text { the network. } \\
\text { 4. Considering it important to be regarded (by other members) as being } \\
\text { professionally competent. } \\
\text { 5. Considering it important to be regarded (by other members) as being } \\
\text { reliable and trustworthy. } \\
\text { 6. Fulfilling obligations to other members to maintain a firm's reputation } \\
\text { within the network. }\end{array}$ \\
\hline
\end{tabular}

Access to the Zea Partners network is restricted based on a firm's reputation and performance in the OSS community as well as previous interactions with member firms. It is not just about keeping numbers low; it is a strategic restriction. Firms have to fit in with the macroculture and needs of the network, and exhibit a commitment to Zea Partners' success. The network's macroculture is typical of values associated with OSS communities: the involvement of users (customers) as equal partners, the visibility of actions, etc. However, this macroculture is evident not just as a shared set of values (including beliefs, language, etc.) as proposed by Jones et al. (1997) but also includes the mechanisms by which these ideas are expressed and shared among members. Consistent with extant research on social mechanisms, restricted access, reputation, macroculture, and collective sanctions were cited by study participants as enabling the coordination and safeguarding of exchanges between network members. However, our analysis revealed 
that the functioning of these mechanisms, and how they relate to coordination, adaptation, and safeguarding exchanges, followed a different pattern from the one proposed by Jones et al.

\subsection{How Social Mechanisms Facilitate the Coordination of Exchanges}

Restricted access facilitates coordinating exchanges by establishing routines for members to work together. The network's founder stated that the network is "still at an early enough stage that we are able to work together on a person-to-person basis" but it assists members by having "standing contracts, customer references etc on file...so the friction in assembling a team gets lowered." However, as the network grows he, acknowledges the need to develop "a common methodology, a common way of thinking about a problem, assigning work, tracking results, reporting bugs." Coordination costs are reduced by increasing visibility in the network, thereby facilitating coordination. The network's founder acknowledges the importance of transparency in the community when he says that

the best barometer is the way people act in the community. If they are competent developers, then you can see them send mails to the mailing lists, do check-ins, and file bug reports, write papers for conferences, etc. There are a multitude of avenues available to show their competence. If someone is invisible from all those avenues, that says something.

The network has adopted deliberate membership requirements that facilitate a component-based approach to work allocation. The owner of Plone Solutions recognizes the importance of this sort of network design when he says that

there is no single point of failure; you can swap out components or companies. If one company is not talented enough or does not have the domain knowledge to do this particular thing we normally have another company that has...it's very agile and flexible.

Restricted access also facilitates coordinating exchanges by giving network members a voice in decision making. The owner of Reflab says that members "also have the ability to steer...the whole product idea was something that we could approve or reject." The owner of Bubblenet reaffirms this point when he says that "[members] talk a lot... which gives me the chance to give my opinion and maybe shape part of the process." Finally, restricted access facilitates mutual adjustment by reducing the variances that parties bring to the exchanges and establishing a routine for working together. Zea's founder notes that "about 50 percent of the problem is solved by working the same way we worked [in OSS communities]. The companies have a set of tools, a way of working together, a common culture and ways of communication that we use on Zea projects."

Macroculture was found to facilitate coordinating exchanges in a number of ways. First, a culture of network agility is fostered among member firms in order to enable coordination. Zea's founder says that they "want to define this OSS business model idea. 
Instead of having the cathedral model of Accenture, we want to have multiple players in multiple countries. We can move things around as new trends or specialities emerge." Coming from the OSS community, there is a preexisting macroculture that is important for ensuring new members fit into the network's culture. Zea's founder says that Zea Partners “are going to focus on people who've already decided they're interested in OSS, not people who don't understand value and values. The prime consideration is to make sure that the fabric that holds this experiment together doesn't get torn." Creating a sense of mutual interest or "good karma" is also seen as an important aspect of macroculture that facilitates coordination. The chief architect of Plone Solutions says that "we have not been taking Zea projects because there are other companies that need the work more. It's partly that we are busy and partly that we are trying to be nice to other people; they're good people and they should have more work than they currently do." Preventing the fear of lock-in among participants is an important factor in creating a sense of macroculture in the network. The owner of Bubblenet makes the point that "the part that seduces me is that someone who joins can leave easily. This is very important because it helps in reducing people's fears; this means they work better together." Part of the macroculture in the network is concerned with reducing information and knowledge asymmetries inside and outside the network. The director of Blue Fountain acknowledges the need for member firms to learn from each other when he says "it's very important that we coordinate, share best practice, learn from each other, leverage our collective experience." Zea's founder recognizes the importance of involving the client in the OSS community to reduce information asymmetry when he says that "the customer is a participant not a recipient. We want to engage with their in-house staff and teach them how to become OSS developers, how to participate in the community, ask questions, etc., even show them how to contribute back."

Contrary to the model proposed by Jones et al. (1997), our study revealed that coordinating exchanges is facilitated by the desire of members to demonstrate that they adhere to the values of the network by acting in a manner that is considered to be competent and professional. The consequences of not acting in this manner include damage to their reputation as well as exclusion from projects and/or the network (i.e. , collective sanctions). Thus, they strive to be flexible and transparent in their dealings with other members, and to abide by the norms that govern participation in open source development communities. We, therefore, conclude that collective sanctions, as well as restricted access and macroculture, facilitate coordinating exchanges.

\subsection{How Social Mechanisms Facilitate Safeguarding Exchanges}

The study illustrates that reputation and collective sanctions facilitate safeguarding exchanges as predicted by the Jones et al. (1997) model. Indeed, collective sanctions are seen to facilitate safeguarding exchanges in the same manner as they facilitate coordinating exchanges (see the previous section). However, the study revealed the social mechanisms that facilitate safeguarding exchanges include macroculture rather than restricted access as previously predicted.

Reputation facilitates the safeguarding of exchanges by acting as a prerequisite for participation. Zea's founder says that "getting in the network is only the first part. If you want to do transactions with others in the network, you need to show yourself to be 
competent and professional." Reputation also has an effect by rewarding good behavior. The owner of Bubblenet says that "getting a reputation in the community is very important; other companies will send me projects that they cannot handle." Reputation also has economic consequences. The owner of Bubblenet remarks that "my first contracts were subcontracts from other Zope companies. That gave me enough presence in the community to switch to my own contracts, but not ones as small as before. Being part of Zope Europe has helped a lot."

Macroculture facilitates the safeguarding of exchanges by balancing commercial interests with network objectives. The owner of Bubblenet says that "most of us are in this for the lifestyle rather than purely to make money; that's difficult to formalize." The owner of Zest Software says that "you get respect by helping other people; you earn the right to ask more questions and favors." Another aspect of the macroculture in the network is taking an ethical approach to commercial issues. The director of Blue Fountain says that "we tell our customers we do three things: transparency, integrity, and honesty. If there's a problem, we'll always put our hand up." The chief architect of Plone Solutions says that "we wouldn't leave a client hanging just because it didn't suit us to go back to that deployment. It's a value thing." Zea's founder acknowledges the importance of creating an environment of trust when he says that "there's a trust vector when it comes to organizing and assigning work that people can make money on. That person has to be perceived as being neutral and competent."

\subsection{Enabling Network Effectiveness}

Finally, the study also examined network effectiveness using the work of De Wever et al. (2005). Members consider the network effective as it allows them to access and share strategic resources. They cited the ability to access and leverage the skill base of other firms, share customer contacts, compete for larger contracts, share business experiences and expertise (e.g., project management), and enjoy an enhanced reputation as a result of membership. According to Zea's founder, such resource sharing allows Zea to "take the whole product and make it offerable by anyone in the network. It has so many benefits on profitability it's just amazing." Our analysis revealed coordination and adaptation to be essential for firms to offer the whole product; thus affecting access to and exchange of strategic resources. In addition, the exchange of strategic resources was dependant on such exchanges being safeguarded.

\section{CONCLUSION}

Our study has shown that a business network model can be particularly effective in delivering the whole product needed to commercially exploit peer produced software. OSSNs, thus, directly address key challenges in the commercialization of open source software, and are of interest to both research and practice. The IT infrastructure utilized by OSSNs builds upon the collaborative development and communication environments found in OSS communities, and is focused on enabling rich, transparent interactions between firms. This is in contrast to the transaction-oriented focus of other interorganizational systems. As a result of this type of IT infrastructure, the ways in which OSSNs 
overcome exchange problems contrast with other business networks in that social mechanisms play a primary role in coordinating and safeguarding exchanges among participants (see Table 2) and thus enable the access to and transfer of strategic resources (Figure 2).

Table 2. How Social Mechanisms Facilitate Coordinating and Safeguarding Exchanges

\begin{tabular}{|c|c|c|}
\hline $\begin{array}{c}\text { Social } \\
\text { Mechanism }\end{array}$ & Coordination & Safeguarding \\
\hline $\begin{array}{l}\text { Restricted } \\
\text { Access }\end{array}$ & $\begin{array}{l}\text { Facilitating the establishment of } \\
\text { routines for working together. } \\
\text { Reducing coordination cost through } \\
\text { increased visibility. } \\
\text { Adopting deliberate membership. } \\
\text { requirements facilitating a component- } \\
\text { based approach to work allocation. } \\
\text { Giving members a voice in decision } \\
\text { making. } \\
\text { Reducing variances that parties bring } \\
\text { to the exchanges (facilitates mutual } \\
\text { adjustment). } \\
\text { Establishing routines for working } \\
\text { together. }\end{array}$ & \\
\hline Macroculture & $\begin{array}{l}\text { Fostering a culture of network agility. } \\
\text { Ensuring new members fit in to } \\
\text { network's culture. } \\
\text { Creating a sense of mutual interest } \\
\text { (good Karma). } \\
\text { Preventing fear of lock-in. } \\
\text { Reducing information/knowledge } \\
\text { asymmetries. }\end{array}$ & $\begin{array}{l}\text { Balancing commercial } \\
\text { interests with network } \\
\text { objectives. } \\
\text { Taking an ethical approach to } \\
\text { commercial issues. } \\
\text { Creating an environment of } \\
\text { trust. }\end{array}$ \\
\hline $\begin{array}{l}\text { Collective } \\
\text { Sanctions }\end{array}$ & $\begin{array}{l}\text { Encourages firms to be transparent in } \\
\text { their dealings with other members. } \\
\text { Encourages firms to act in a manner } \\
\text { that is regarded as competent and } \\
\text { professional. } \\
\text { Encourages firms to behave in line } \\
\text { with network expectations. }\end{array}$ & $\begin{array}{l}\text { Encourages firms to be } \\
\text { transparent in their dealings } \\
\text { with other members. } \\
\text { Encourages firms to act in a } \\
\text { manner that is regarded as } \\
\text { competent and professional. } \\
\text { Encourages firms to behave in } \\
\text { line with network } \\
\text { expectations. }\end{array}$ \\
\hline Reputation & & $\begin{array}{l}\text { Acting as a prerequisite for } \\
\text { participation. } \\
\text { Rewarding good behavior. } \\
\text { Ensuring that there are } \\
\text { economic consequences of } \\
\text { reputation. }\end{array}$ \\
\hline
\end{tabular}




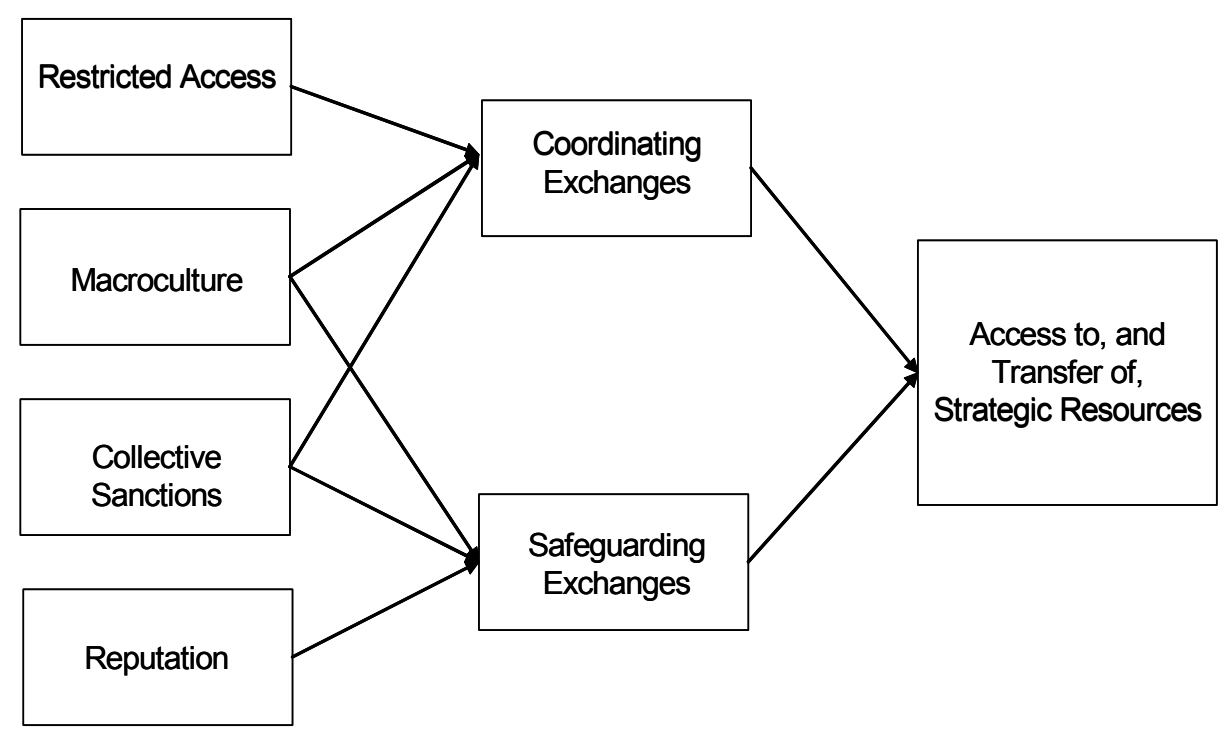

Figure 2. Overcoming Exchange Problems in OSSNs

A comparison of Figure 2 with extant research (as represented in Figure 1) reveals that the role of individual social mechanisms in facilitating coordinating and safeguarding exchanges is different from that envisaged by previous work (e.g., Jones et al. 1997, 1998). In particular, restricted access is not seen as facilitating safeguarding, while both macroculture and collective sanctions have greater influence than previously envisaged.

Our study found evidence that collective sanctions played a more significant role in coordinating and safeguarding exchanges than envisaged by previous work. Collective sanctions were evident as (1) damage to a firm's reputation, (2) exclusion from ongoing projects, or (3) expulsion from the network. Consequently collective sanctions were particularly potent given the importance of both reputation and the bidding leverage of the network to commercial success. Macroculture is seen to play a central role in the governance of OSSNs and, contrary to previous beliefs, has a role to play in both facilitating coordinating and safeguarding exchanges. Macroculture is central to effectiveness because (1) it allows firms to work easily without the imposition of formal agreements, and (2) the specific macroculture observed in OSSNs reflects that of OSS communities, there is an emphasis on collaboration, sharing, and the preservation of the commons. In addition, macroculture is evident not just as a shared set of values (including beliefs, language, etc.), but also includes the mechanisms by which these ideas are expressed and shared among members. This represents a richer view of culture, more typical of the thinking of Hannertz (1992) on cultural complexity in information societies than of Jones et al. (1997).

To conclude, our study suggests that as social mechanisms can be used to effectively overcome exchange problems in OSSNs, such networks have less overhead vis-à-vis coordination and safeguarding than if they relied exclusively on formal or legal mechanisms. Additionally, our study suggests that the competencies required to engage 
in such networks and participate in socially enabled exchanges can be acquired through prior participation in the open source community development process, where similar mechanisms have been observed. Together, these imply that the barrier of entry to OSSN formation, operation, and participation is potentially lower for firms emerging from the OSS community context than for firms coming to open source from the outside. Finally, it is evident that the challenges of productizing OSS are typical of developments in the production and use of other complex product and service offerings as discussed by Davidow and Malone (1992). Therefore, the findings of this study may have implications for networks of SMEs operating in other sectors. However, the methodology utilized for the study was exploratory, and thus the findings need further investigation. This study should be duplicated as part of the process of validating its findings in a context that is not just exploratory. In particular, further research is needed to replicate the study by studying governance mechanisms in a wider variety of networks.

\section{Acknowledgments}

This work has been financially supported by the Irish Research Council for the Humanities and Social Sciences (IRCHSS), the Science Foundation Ireland award to Lero - the Irish Software Engineering Research Centre, and by the EU FP6 project OPAALS (Open Philosophies for Associative Autopoietic Digital Ecosystems).

\section{References}

Alter, C., and Hage, J. 1993. Organizations Working Together, London: Sage Publications. Benbasat, I, Goldstein, D. K., and Mead, M. 1987. "The Case Study Research Strategy in Studies of Information Systems," MIS Quarterly (11:3), pp. 369-386.

Benkler, Y. 2002. "Coase's Penguin, or Linux and the Nature of the Firm," The Yale Law Journal (112:3), pp. 369-446.

Benkler, Y. 2006. The Wealth of Networks: How Social Production Transforms Markets and Freedom, New Haven, CT: Yale University Press.

Bergquist, M., and Ljungberg, J. 2004. "The Power of Gifts: Organizing Social Relationships in Open Source Communities," Information Systems Journal (11:4), pp. 305-320.

Cash, J. I., and Konsynski, B. R. 1985. "IS Redraws Competitive Boundaries," Harvard Business Review (63:2), pp. 131-142.

Clemons, E. K., and Row, M. C. 1992. "Information Technology and Industrial Cooperation: The Role of Changing Transaction Costs," Journal of Management Information Systems (9:2), pp. 9-28.

Davidow, W. H., and Malone, M. S. 1992. The Virtual Corporation, New York: HarperCollins.

De Wever, S., Martens, R., and Vandenbempt, K. 2005. "The Impact of Trust on Strategic Resource Acquisition through Interorganizational Networks: Towards a Conceptual Model," Human Relations (58:12), pp. 1523-1543.

Eisendhardt, K.M. 1989. "Building Theories from Case Study Research," Academy of Management Review (14:4), pp. 532-550.

Feller, J., and Fitzgerald, B. 2002. Understanding Open Source Software Development, London; Addison-Wesley.

Finnegan, P., Galliers, R. D., and Powell, P. 2003. "Applying Triple Loop Learning to Planning Electronic Trading Systems," Information Technology and People (16:4), pp. 461-483.

Fitzgerald, B. 2006. "The Transformation of Open Source Software," MIS Quarterly (30:3), pp. 587-598. 
Galaskiewicz, J. 1985. “Interorganizational relations," Annual Review of Sociology (11), pp. 281-304.

Gallivan, M. J. 2001. "Striking a Balance Between Trust and Control in a Virtual Organization: A Content Analysis of Open Source Software Case Studies," Information Systems Journal (11:4), pp. 277-304.

Granovetter, M. 1992. "Problems of Explanation in Economic Sociology," in Networks and Organizations: Structure, Form, and Action, N. Nohria and R. C. Eccles (eds.), Cambridge, MA: Harvard Business School Press, pp. 25-56.

Hannertz, U. 1992. Cultural Complexity: Studies in the Social Organization of Meaning, New York: Columbia University Press.

Henderson, J. C. 1990. "Plugging into Strategic Partnerships: The Critical IS Connection," Sloan Management Review (31:3), pp. 7-18.

Jones, C, Hesterly, W, and Borgatti, S. 1997. "A General Theory of Network Governance: Exchange Conditions and Social Mechanisms," Academy of Management Review (22:4), pp. 911-944.

Jones, C., Hesterly, W., Fladmoe-Lindquist, K., and Borgatti, S. 1998. "Professional Service Constellations: How Strategies and Capabilities Influence Collaborative Stability and Change," Organization Science (9:3), pp. 396-410.

Kaufman, F. 1966. "Data Systems that Cross Company Boundaries," Harvard Business Review (44:1), pp. 141-155.

Krishnamurthy, S. 2005. "An Analysis of Open Source Business Models," in Perspectives on Free and Open Source Software, J. Feller, B. Fitzgerald, S. A. Hissam, and K. R. Lakhani (eds.), Cambridge, MA: MIT Press, pp. 279-296.

Madill, A., Jordan, A., and Shirley, C. 2000. "Objectivity and Reliability in Qualitative Analysis: Realist, Contextualist and Radical Constructionist Epistemologies," British Journal of Psychology (91:1), pp. 1-20.

Markus, M. L., Manville, B., Agres, C. E. 2000. "What Makes a Virtual Organization Work?," Sloan Management Review (42:1), pp. 13-26.

Moore, G. 1999. Crossing the Chasm, Harper-Perennial, New York,.

Oliver, C. 1990. "Determinants of Interorganizational Relationships: Integration and Future Directions," Academy of Management Review (15:2), pp. 241-265.

Raymond, E. S. 2001. The Cathedral \& the Bazaar, Sebastopol, CA: O'Reilly.

Sagers, G. 2004. "The Influence of Network Governance Factors on Success in Open Source Software Development Projects," in Proceedings of the $25^{\text {th }}$ International Conference on Information Systems, R. Agarwal, L. Kirsch, and J. I. DeGross (eds.), Washington, DC, December 12-15, pp. 427-438.

Stafford, T. 2002. "Trust, Transactions, and Relational Exchange: Virtual Integration and Agile Supply Chain Management," in Proceedings of the $8^{\text {th }}$ Americas Conference on Information Systems, R. Ramsower and J. Windsor (eds.), Dallas, TX, August 9-11, pp. 2365-2371.

Strauss, A., and Corbin, J. 1990. Basics of Qualitative Research: Grounded Theory Procedures and Techniques, Newbury Park, CA: Sage Publications.

Szczepanska, A. M., Bergquist, M., and Ljunberg, J. 2005. "High Noon at OS Corral: Duals and Shootouts in Open Source" in Perspectives on Free and Open Source Software, J. Feller, B. Fitzgerald, S. A. Hissam, and K. R. Lakhani (eds.), Cambridge, MA: MIT Press, pp. 431-446.

Timmers, P. 1999. Electronic Commerce: Strategies and Models for Business-to-Business Trading, New York: Wiley.

West, J. 2003. "How Open Is Open Enough? Melding Proprietary and Open Source Platform Strategies," Research Policy (32), pp. 1259-1285.

Woods, D., and Guliani, G. 2005. Open Source for the Enterprise, Sebastapol, CA: O'Reilly Media. 
Van de Ven, A. H. 1976. "On the Nature, Formation and Maintenance of Relations Among Organizations," Academy of Management Review (1:4), pp. 24-36.

Van de Ven, A. H., and Walker, G. 1984. "The Dynamics of Interorganizational Coordination," Administrative Science Quarterly (29:4), pp. 598-621.

Yin, R. K. 1994. Case Study Research, Design and Methods, Newbury Park, CA: Sage Publications.

\section{About the Authors}

Joseph Feller received his Ph.D. from University College Cork, where he is currently a senior lecturer in Business Information Systems. He has published four books and his work has been published in a number of international journals and conferences, including The Information Systems Journal, Journal of Strategic Information Systems, Journal of Information Technology Theory and Application, Software Process-Improvement and Practice, IEE ProceedingsSoftware, and Annals of Cases on Information Technology. He has also published over 60 technical and practitioner articles, and is a frequent contributor to the Cutter Consortium. He was the program chair (with Alberto Sillitti) for the Third International Conference on Open Source Systems and was the founder and chair of the IEEE/ACM Workshop Series on Open Source Software Engineering (hosted by the International Conference on Software Engineering). Joseph can be reached at jfeller@afic.ucc.ie.

Patrick Finnegan received his Ph.D. from the University of Warwick, England, and is currently a senior lecturer in Information Systems at University College Cork, Ireland. His research on interorganizational systems and electronic business has been published in a number of international journals and conferences, including Information Technology and People, DATABASE, The Information Systems Journal, The International Journal of Electronic Commerce, Electronic Markets, and Information Resources Management Journal. He is currently an associate editor of Information Systems Journal and president of the Irish Association for Information Systems. Patrick can be reached at p.finnegan@ucc.ie.

Brian Fitzgerald received his Ph.D. from the University of London and currently holds the Frederick A Krehbiel II Chair in Innovation in Global Business and Technology at the University of Limerick, where he is also director of the Lero Graduate School in Software Engineering (www.lgsse.ie). His research interests include open source software, agile methods, and distributed software development. He has published 10 books and his work has appeared in most leading IS journals and conferences. He has served as a guest senior editor for several prominent journals, including Information Systems Research, Communications of the ACM, European Journal of Information Systems, and Information Systems Journal. Brian can be reached at brian.fitzgerald@ul.ie.

Jeremy Hayes is a lecturer in Business Information Systems at University College Cork. His research interests are in the area of electronic business models, interorganizational systems, and business agility. He has published his research findings at international conferences and journals, including the European Conference on Information Systems, the Collaborative Electronic Commerce Technology and Research Conference (CollECTeR Europe ), IFIP 8.3, Journal of Database Management, and European Journal of Operational Research. Jeremy can be reached at j.hayes@ucc.ie. 